\title{
Health education and the pedagogical role of the nurse: Nursing students learning in the clinical setting
}

\author{
Kirsten Margrethe Halse ${ }^{1}$, Marianne Fonn ${ }^{2}$, Bjørg Christiansen ${ }^{1}$ \\ 1. Department of Nursing, Faculty of Health Sciences, Oslo and Akershus University College of Applied Sciences, Norway. \\ 2. Oslo University Hospital, Oslo, Norway.
}

Correspondence: Kirsten Margrethe Halse. Address: Department of Nursing, Faculty of Health Sciences, Oslo and Akershus University College of Applied Sciences. Norway. Email: Kirsten.Halse@hioa.no

Received: June 3, 2013

DOI : $10.5430 /$ jnep.v4n3p30

Accepted: August 25, 2013

URL: http://dx.doi.org/10.5430/jnep.v4n3p30
Online Published: October 16, 2013

\section{Abstract}

Background: Health education has been regarded as an important aspect of nursing for years. To be able to provide health education, nursing students need to know about the content of health education programs and the pedagogical role of the nurse.

Methods: For nursing students to acquire knowledge about the pedagogical role of the nurse, they carried out a learning assignment where they explored the pedagogical role of the nurse in the ward for one week of an eight-week clinical rotation. A study was then conducted to explore whether the learning assignment influenced the students' awareness of the nurse's pedagogical role. Twenty-three third-year bachelor of nursing students, 12 in 2007 and 11 in 2008, participated in focus group interviews.

Results: The findings showed that the students became more aware of nurses' pedagogical role after the one week of exploring patient education with ward nurses. The students increased awareness was founded on their experiences, which were that the nurses seldom planned the health education and information given. Further that the nursing staff did not utilize planned educational materials for their patient education and that they seldom documented health education. Despite these finding, the patients were generally informed during caring interactions.

Conclusions: A learning assignment related to the nurses' pedagogical role seemed to have increased the students' critical awareness of the nurse's pedagogical role and the legal demands related to the obligation of nurses to educate patients.

\section{Key words}

Students' learning, Clinical study, Nurses' pedagogical role, Health education

\section{Introduction}

Health education has been regarded as an important aspect of nursing for years ${ }^{[1,2]}$. Patient education is as important now as ever ${ }^{[2]}$. Health education is defined as "the communication of health-related information and development of the attitudes, skills, and confidence necessary to enable people to take action to improve their health" ${ }^{[3]}$. In relation to the education of patients, the term pedagogy is used as a comprehensive term for all teaching activities ${ }^{[1]}$. Strategies include one to one advice, encouragement, giving explanations orally and written information, instructing or telling patients about 
health information, counseling and asking questions ${ }^{[3,4]}$. To be able to provide health education to patients, the nursing student needs to know the content of health education programs and the pedagogical role of the nurse.

Internationally, the importance of health education is illuminated through the vast amount of nursing research studies conducted on the subject ${ }^{[1,2,5-13]}$. In Norway, the significance of health education is specified in the Norwegian Health Personnel Act of 1999. It is therefore important to emphasize the pedagogical role of the nurse in nursing schools ${ }^{[14]}$.

In the nursing curriculum of the baccalaureate degree program at "Pilestredet campus, Oslo and Akershus University College of Applied Sciences", the students learn about nurses' pedagogical role in lectures and in the skills laboratory through role-playing. During clinical studies, students further their learning about this role in situations in which patients require health education. Despite these opportunities, our experience is that students have difficulties grasping this part of nursing, possibly because providing health education is not always obvious in nursing practice. For students to truly understand the pedagogical role of the nurse and the value of health education, it seems important to increase students' awareness of this role.

The major part of health education research is within the area of formal teaching ${ }^{[1]}$. Studies have reported a positive effect of health education on patients. For example, a study of elderly patients' knowledge about their medication showed that their knowledge increased after receiving information from nurses before leaving the hospital ${ }^{[5]}$. In one study regarding the reduction of cancer patients' barriers to pain and fatigue, the results showed that patients who had received four educational sessions on pain and fatigue assessment and management experienced significant improvements in pain and fatigue immediately post intervention, and these improvements were sustained over time ${ }^{[6]}$. The results from another study indicated that one single health conversation encounter had a significant impact on the participants, and so room must be created for pedagogical encounters as part of a cardio-vascular heart disease prevention follow-up in primary healthcare ${ }^{[7]}$. On the other hand, other studies have shown that some patients need more health education than they received in hospital. One study indicated that after discharge after cardiac surgery, women patients needed more information about why postoperative pain management is important beyond simple pain relief. This was the case even though the women were advised by the hospital to take an analgesic, both regularly and as needed, upon returning home ${ }^{[8]}$. Kääriainen \& Kyngä found that $13 \%$ of the staff did not adapt the issues dealt with in patient education to the patient's life situation, and that less than half of the staff asked the patients to give feedback on the patient education ${ }^{[9]}$.

Other studies focus on how the nurse's pedagogical role is performed. In some studies, health education is divided into formal and informal education ${ }^{[1]}$. Informal health education takes place continually as a natural part of nurse-patient interaction, and patients are often taught during various activities ${ }^{[1]}$. In one study, the results indicated that the nurses' daily patient education was largely invisible. This was interpreted as caused by a lack of awareness of patient education among both managers and nurses ${ }^{[10]}$. Another study showed that the nursing staff had quite good knowledge concerning matters involving patient education and good skills to maintain the patient education process, even though there was not always enough time and resources for this ${ }^{[9]}$. Person \& Friberg concluded that health conversation encounters require preparedness and pedagogical awareness, as well as an ability to be attentive to the patients need for understanding and level of motivation for lifestyle changes ${ }^{[7]}$. Health education is not always documented although documentation is part of nurse` educational practices ${ }^{[11,12]}$.

Several studies have focused on nurses' opinions of the pedagogical role ${ }^{[1,4,13,15-17]}$. Some nurses see their role as a health educator as a key function, but also that they are not always able to fulfill this role. For example, Lee \& Lee found that nearly half of the nurses felt they did not impart all the necessary preoperative information to patients. This was attributed to time constraint and nursing workload, communication difficulties and limiting teaching resources. They also suggest that there are somewhat unclear boundaries between nurses and other healthcare professionals regarding their responsibilities in patient education ${ }^{[13]}$. A study of nurses working with elderly patients in a hospital setting showed that most nurses feel confident in their ability to provide health education ${ }^{[18]}$. However, not all nurses feel this way. Bergh, et 
$a l$. found that nurses are not always sure of whom to address and what to teach and/or inform ${ }^{[10]}$. Danielson \& Berntsson reported that RNs feel there is little agreement between the demands of nurses' role as health educators and preparation during their study ${ }^{[16]}$. By contrast, Lamiani \& Furey found that nursing studies increased the nurses' ability to act as health educators ${ }^{[17]}$. Lee \& Lee found that nurses who had participated in surgical or perioperative training courses had greater satisfaction with preoperative teaching ${ }^{[13]}$.

In summary, health education has a positive impact on a patient's health situation, but for some patients the health education they receive is not satisfactory. The pedagogical role is also equivocal, because health education has both formal and informal aspects. Not all activities related to health education are performed satisfactorily, and not all nurses feel competent in performing this function. It is therefore necessary to focus more on the role of health educator during nursing education. We did this by planning a learning assignment during a clinical study period in which the focus was on students learning about the pedagogical role of nurses. The students were assigned to explore how the nurse performed her pedagogical role in the ward. The purpose was to increase the students' knowledge of the pedagogical role of nurses and thereby make them better prepared to provide health education in the future.

\section{The learning assignment}

The assignment required the students to focus on how the nurse's pedagogical role was shaped in the ward during one week of an eight-week clinical practice. The ward was populated with 12 students, who worked in groups of two. Two groups of two students (group 1) asked RNs about how they managed their pedagogical role. Students in group 2 observed how an RN applied her pedagogical role. Group 3 asked patients for their opinions about the information received. Group 4 gathered information about the laws and guidelines for health education, and group 5 scrutinized nursing care plans related to this topic. At the end of each day, the students met for $1 \frac{1}{2}$ hours to discuss their experiences and findings, and at the end of the week each group provided a written summary, which was forwarded to the head nurse. The student facilitator and the university college lecturer functioned as tutors.

The content and organization of the learning assignment are presented in detail in Table 1.

Table 1. Content and Organization of the Learning Assignment

\begin{tabular}{|c|c|}
\hline Group 1 & Four students ask the nurses about how they manage their pedagogical role. \\
\hline Group 2 & $\begin{array}{l}\text { Two students observe how a nurse performs the pedagogical role during a 7.5-hour shift and consider the } \\
\text { following questions. } \\
\text { a) What information, advice, and health education does the nurse give to patients and/or their relatives? } \\
\text { b) In what situations does the nurse inform, guide, or teach the patient and/or relatives? } \\
\text { c) How does the nurse inform, guide, and teach patient/or relatives? }\end{array}$ \\
\hline Group 3 & Two students ask patients their opinion of the information, guidance, and health education they have received. \\
\hline Group 4 & $\begin{array}{l}\text { Two students: } \\
\text { a) Gather information about the relevant laws and guidelines at both the local hospital and national levels; } \\
\text { b) Try to discover what the students need to learn to manage this specific function. }\end{array}$ \\
\hline Group 5 & $\begin{array}{l}\text { Two students: } \\
\text { a) Analyze patient files to find nursing documentation concerning health education; } \\
\text { b) Check routines, guidelines, and relevant literature referring to the nurse's pedagogical role in the ward. }\end{array}$ \\
\hline
\end{tabular}

\section{Ethical considerations concerning the learning assignment}

The faculty granted permission to let students perform the learning assignment and the hospital granted permission to have students ask and observe the staff. The Privacy and Data Protection Office, CEO Executive Staff at the hospital were informed and made no objections regarding students asking patients. Since the RNs were not participants in the study, but only took part in the learning assignment in as much as they were only asked and observed by students about how they 
managed their pedagogical role, it was not necessary for neither the staff nor the patients sign consent form. Both patients and nurses were asked by students if they were willing to participate and only did so if they wanted to.

\section{Evaluation of the learning assignment}

A study was then conducted to explore whether the learning assignment influenced the students' awareness of the nurses' pedagogical role. To gain better insights into the results of the learning assignment, the teacher in cooperation with a colleague from the Institute of Nursing led focus group interviews with the students. The following research question was formulated: How did the learning assignment about the nurse's pedagogical role influence the students' learning and perception of this role?

\section{Method}

\subsection{Participants}

Twenty-three third-year bachelor of nursing students, 12 in 2007 and 11 in 2008, performed the learning assignment. All of them agreed to participate in the study.

\subsection{Focus group interviews}

The students were divided into two groups of five or six students, and four interviews were conducted. The interviews took place one week after the assignments in 2007 and 2008. Focus group sessions are discussions that take advantage of group dynamics for accessing rich information ${ }^{[19]}$. An interview guide was developed and comprised questions related to the students' experiences of how the pedagogical role was performed in the ward and what they learned by doing the assignment. The moderator who attended the interviews had no prior knowledge of the students. The teacher attended as a co-moderator. The interviews were conducted at the hospital, lasted for about 60 minutes, and were tape-recorded and transcribed verbatim.

\subsection{Data analyses}

The chosen unit of analysis was the group and not its individual members because opinions and views were produced in a group situation ${ }^{[19]}$.

Kvale \& Brinkmann's guidelines for qualitative research, which involve a back-and-forth process between the parts and the whole, guided the analysis. The analysis was based on Kvale \& Brinkmann's three levels of interpretation: selfunderstanding, common sense, and theoretical perspective ${ }^{[20]}$. The data were read repeatedly and discussed by the authors to gain a general picture before they were condensed into preliminary meaning units. These meaning units were sorted into three categories across all four interviews: 1) students' perception of the pedagogical role; 2) students' perception of formal and informal education; and 3) students' perspectives of documenting health education. The findings are presented based on these categories.

Previous research covers the theoretical perspective from which the findings are discussed. This analytical process implied a transition from description and conceptualization to a more comprehensive understanding.

\subsection{Ethical considerations}

Students who participated in the focus group interviews received written information. They were informed that participation was voluntary and that they had the right to withdraw at any time. In the presentation of data, no names or other identifying characteristics are used. All students agreed and signed a written consent form. The Norwegian Social Science Data Services was also informed and made no objections. 


\section{Findings}

\subsection{Students' perception of the pedagogical role}

The general opinion among the students was that the assignment increased their awareness of the pedagogical role of the nurse. This opinion was gained by viewing the topic from different angles and through discussions with fellow students:

I am more aware of it now than before. When I am in the patients' room it is always in the back of my mind. I think that this is the most important thing I have experienced in working with this. I am more concerned with this role now and have seen how important it is.

The students believed that most of the nurses had difficulties distinguishing between the types of pedagogical methods generally used in health education: to inform, guide, and teach. Quite a few of the students expressed that they found this distinction challenging: "We learned something about the different definitions, but they still intertwine."

The students had difficulty comparing the patients' and nurses' opinions of the health education given because the patients' and nurses' understanding of the pedagogical concepts varied. The students observed that the nurses mainly informed and guided the patient, and that there was less direct teaching of the patient.

The students observed a mix of experiences in the nurses' ability to adjust to the patients' level of comprehension. One student remarked, "Some of the nurses were very good; they just said one sentence that said it all, but some use several sentences.”

\subsection{Students' perspectives on formal and informal education}

The students observed that the patients received a great deal of information from the RNs in nurse-patient interactions throughout the day, but there seemed to be little formal patient teaching taking place either when the patients were hospitalized or at discharge. The students perceived that more formal information was given during the medical rounds. The students found it difficult to grasp how the responsibility for health education was divided between the doctors and RNs.

Sometimes the doctors leave it to nurses to inform the patient about the diagnoses and medication-maybe because of the lack of time?

Students did not observe that the RNs went back to the patients after the medical rounds to question whether the patient had understood the information:

I have been attending the medical rounds where the doctor informed the patient about the diagnosis and date for discharge from hospital, but I didn't see the nurses going back to make sure the patient understood the information or any written documentation in the patient file that information had been given or was understood.

The students noted that patients sometimes received information during interactions that was not related to the procedures taking place. For example, a patient might be informed about discharge while being helped with personal hygiene. When students asked the patient afterwards, the patient did not remember having been informed about discharge.

The students observed that the patients did not always perceive information given during practical situations as health education. Generally, the students' perception was that information from the nurses was given to patients to ease practical situations: "Most of what I observed happened during practical situations; there was no plan or special strategy."

The students observed that the information was mainly given orally and was not written. They said that they had had trouble finding patient information brochures about procedures, examinations, and daily routines in the ward. The students 
also reflected on the use of brochures: "It is so easy to hand someone a brochure at discharge, but this still does not mean the information is understood."

When the students asked the nurses about what they considered to inhibit the delivery of adequate patient information, lack of time was often mentioned. Some students reflected on the future and envisioned that, as newly educated nurses, it would be difficult to find the time to prioritize health education.

\subsection{Students' perspectives on documentation of health education}

The students had no problem finding national laws and guidelines concerning health education. Through interviews with staff from the Centre for Learning and Mastering, the students became aware that the center had more guidelines for health education than the ward: "I feel that we have become more aware of the guidelines." They did, however, experience difficulty in finding the hospital's internal guidelines on how to deliver and document health education and were concerned about the lack of documentation in the patient files: "You are supposed to document the patients' basic needs and progress; there ought to be a mark for patient education." According to the students, there was no obvious place in the documentation system for the nurses to document the delivery of health education. Insufficient documentation seemed to trigger the students' awareness of the importance of keeping a record: "It is always in the back of my head now: when information is given it also needs to be documented. And we are obliged to inform the patients." The students found that information given to relatives was documented more often.

\section{Discussion}

The findings show that the students increased their awareness of the pedagogical role of nurses through the assignment, even though they observed that the nurses seldom planned the given education and that patients were generally informed during caring interactions. These findings are consistent with studies showing that health education is an integrated part of nursing ${ }^{[1,10]}$. The students found that the RNs and patients have a great deal of interaction throughout the day, and the continual flow of information is both natural and valuable. However, one consequence is that the nurses' pedagogical role may be unclear for students. Formal health education is a vital component of direct patient care. The students became aware of this even though they did not observe nurses carry out formal health education.

There is a need to focus on formal health education, but informal pedagogical activities during nursing interventions must also be acknowledged. The students observed that the patients received a great deal of information throughout the day. This way of teaching/informing patients frequently occurs ${ }^{[1,10]}$. The informal situations should be acknowledged because they can have pedagogical potential and can transform into education that is more formal if nurses are able to grasp the need of the patient. To obtain a deeper understanding of health education, the challenge for both RNs and students is to become more aware of this distinction and to recognize that informal and formal health education are each important in their own way.

The students had trouble finding documentation of given health education in the patients' files, which is also an issue found in other studies ${ }^{[11,12]}$. According to the Patients' Rights Act, the information given should be documented in each patient's file ${ }^{[21]}$. The RNs documented facts about the patients in relation to many aspects of patient care, but documentation of health education seemed scarce. According to the students, there was no obvious place to document the delivery of health education in the documentation system. Another factor could be that the RNs perceived their pedagogical role as an integrated part of their daily routines, as found in other studies ${ }^{[1,10]}$, and thought it would be excessive to document everything. For students, it was not obvious how health education activities should be documented when the RNs seldom documented even more formal nursing interventions. Less documentation of health education is very troubling as the nurses and the hospital should legally be documenting all teaching. Observing that documentation of health education seldom occurred made the students more aware of the demands of documentation of all aspects of patient care. 
It is possible that the RNs were more aware of their pedagogical role, and performed more health education than the students perceived. Even so, the assignment had an important impact on the students' critical awareness in relation to the nurse's pedagogical role. Health education is an increasingly important part of the RN profession ${ }^{[2]}$. According to the Norwegian Patient's Rights Act of 1999, a patient has the right to receive the information needed to understand the illness and treatment as well the risks and possible side effects ${ }^{[21]}$. It is therefore important that students master this role in a comprehensive manner. Studies have noted that students receive inadequate training in the delivery of health education ${ }^{[15,16]}$. To promote health education and to improve students' learning, it seems important to increase RNs' skills and awareness of their pedagogical role. Bergh, et al. state that nurses must become aware that patient education requires visibility and development ${ }^{[10]}$. As emphasized by Ivarsson \& Nilsson, the clinical setting is a significant arena for learning about health education ${ }^{[15]}$. To further the pedagogical role in clinical settings, health care organizations and the managers have a great responsibility for creating a pedagogical climate. Ensuring that guidelines and research on patient education are more available in the ward, customizing the documentation system and promoting discussions about health education are important actions. Bergh, et al. found that managers underestimate the importance of patient education in terms of time allocated and the need for pedagogical competence. Furthermore, they state that managerial support must be recognized as significant in creating better conditions for the performance of nurses' daily patient education ${ }^{[10]}$. In our study, each group of students provided a written summary at the end of the week, which was forwarded to the head nurse. In that way, the manager became informed of the student's experiences. Continued pedagogical education for RNs in the form of courses also seems relevant. Ivarsson \& Nilsson emphasized that nurses who have been working for some time need additional knowledge of pedagogy ${ }^{[15]}$. According to Lee \& Lee and Lamiani \& Furey, continuing education increases nurses' ability to deliver health education ${ }^{[13,17]}$.

\section{Conclusion}

The findings of this study show that the learning assignment increased the students' critical awareness about the nurse's pedagogical role and the legal demands related to this work. What contributed to this increased awareness, we assume, were both the activities the students carried out and also the discussion between the students at the end of each day. Their discussions were related to their experiences and the literature they had found about the pedagogical role of the nurse. This kind of learning assignments can be applied easily to other subjects during clinical placements and may thus help students recognize how professional expectations of the nurse's role are exercised. Further research might investigate whether the students who participated in this learning assignment felt more prepared and confident when delivering health education as RNs compared to other students.

\section{References}

[1] Friberg, F., Andersson, E. P., \& Bengtsson, J. Pedagogical encounters between nurses and patients in a medical ward-a field study. Int J Nurs Stud. 2007; 44(4): 534-544. http://dx.doi.org/10.1016/j.ijnurstu.2005.12.002

[2] Friberg, F., Granum, V., \& Bergh, A. L. Nurses' patient-education work: conditional factors- an integrative review. Journal of Nursing Management.2012; 20: 170-186. http://dx.doi.org/10.1111/j.1365-2834.2011.01367.x

[3] Naidoo, J., \& Wills, J. Foundations for health promotion. Edinburgh, Scotland: Published by Baillière Tindall/Elsevier. 2009. ISBN: 978-0-7020-2965-3.h

[4] Casey, D. Findings from non-participant observational data concerning health promoting nursing practice in the acute hospital setting focusing on generalist nurses. J Clin Nurs. 2007; 16(3): 580-592. http://dx.doi.org/10.1111/j.1365-2702.2006.01557.x

[5] Shen, Q., Karr, M., Ko, A., Chan, D. K., Khan, R., \& Duvall, D. Evaluation of a medication education program for elderly hospital in-patients. Evaluation Studies Research Support, Non-U.S. Gov't. Geriatric Nurs. 2006; 27(3): 184-192. http://dx.doi.org/10.1016/j.gerinurse.2006.03.015

[6] Borneman, T., Koczywas, M., Sun, V.C-Y., Piper, B.F., \& Uman, G. Reducing Patient Barriers to Pain and Fatigue Management. J.J painsymman. 2010; 39(3): 486-500. http://dx.doi.org/10.1016/j.jpainsymman.2009.08.007

[7] Persson, M., \& Friberg, F. The dramatic encounter: experiences of taking part in a health conversation. J Clin Nurs. 2009; 18: 520-528. 
[8] Leegaard, M., Rustøen, T., \& Fagermoen M.S. Interference of Postoperative Pain on Women`s Daily Life after Early Discharge from Cardiac Surgery. Pain Management Nursing. 2010; 11(2): 99-107. PMid:20510840 http://dx.doi.org/10.1016/j.pmn.2009.04.001

[9] Kääriäinen, M., \& Kyngäs. H. The quality of patient education evaluated by the health personnel. Scand J Caring Sci. 2010; 24: 548-556.

[10] Bergh, A-L., Karlsson J., Persson E. \& Friberg F. Registered nurses' perceptions of conditions for patient education - focusing on organizational, environmental and professional cooperation aspects. JONM. 2012; 20 (6): 758-770. http://dx.doi.org/10.1111/j.1365-2834.2012.01460.x

[11] Avsar, G., \& Kaşikçi. M. Evaluation of patient education provided by clinical nurses in Turkey. Int. J Nurs Prac. 2011 ; 17 (1): 67-71. http://dx.doi.org/10.1111/j.1440-172X.2010.01908.x

[12] Bergh, A. L., Bergh, C. H., \& Friberg, F. How do nurses record pedagogical activities? Nurses' documentation in patient records in a cardiac rehabilitation unit for patients who have undergone coronary artery bypass surgery. Evaluation Studies. J Clin Nurs. 2007; 16(10): 1898-907. http://dx.doi.org/10.1111/j.1365-2702.2007.01810.x

[13] Lee, C. K. \& Lee, I. F-K. Preoperative patient teaching: the practice and preparations among surgical ward nurses. J Clin Nurs. 2012; 22: 2551-2561. http://dx.doi.org/10.1111/j.1365-2702.2012.04345.x

[14] Norwegian Ministry of Health and Care Services Act of 2nd July 1999, no 64 relating to health personnel etc. Oslo Norwegian Ministry of Health and Care Services, 1999. [The Health Personnel Act] Revised June 2013. Available from: http://lovdata.no/all/nl-19990702-064.html

[15] Ivarsson, B., \& Nilsson, G. The subject of pedagogy from theory to practice- the view of newly registered nurses. Nurse Educ Today. 2009; 29(5): 510-515. http://dx.doi.org/10.1016/j.nedt.2008.11.009

[16] Danielson, E., \& Berntsson, L. Registered nurses' perceptions of educational preparation for professional work and development in their profession. Nurse Educ Today. 2007; 27(7): 900-908. PMid:17336430 http://dx.doi.org/10.1016/j.nedt.2006.12.007

[17] Lamiani, G., \& Furey, A. Teaching nurses how to teach: an evaluation of a workshop on patient education. Clinical Trial. Patient, Educ Couns. 2009; 75(2): 270-273. http://dx.doi.org/10.1016/j.pec.2008.09.022

[18] Kelley, K., \& Abraham, C. Health promotion for people aged over 65 years in hospitals: nurses' perceptions about their role. J Clin Nurs. 2007; 16(3): 569-579. http://dx.doi.org/10.1111/j.1365-2702.2006.01577.x

[19] Polit, D. F., \& Beck, C. T. Nursing research: Generating and Assessing Evidence for Nursing Practice. Philadelphia, PA; Lippincott Williams \& Wilkins.2008.

[20] Kvale, S., \& Brinkmann, S. Interviews: learning the craft of qualitative research interviewing. Los Angeles: CA: Sage.2009.

[21] Norwegian Ministry of Health and Care Services The Act of 2 July 1999 No. 63 relating to Patients' Rights. Oslo. Norwegian Ministry of Health and Care Services, 1999. Revised Des. 2012. Available from: http://lovdata.no/all/nl-19990702-063.html 